OPTICA ACTA, 1982, vol. 29, No. 4, 493-499

\title{
Removing ambiguities in surface roughness measurement
}

\author{
K. LEONHARDT and H. J. TIZIANI \\ Institut für Technische Optik, Univ. Stuttgart, Pfaffenwaldring 9, \\ 7000 Stuttgart 80, F.R. Germany
}

(Received 17 November 1981)

\begin{abstract}
A new method is presented for the measurement of surface roughness in the range $R_{\mathrm{a}} \approx 0.05-10 \mu \mathrm{m}$. The data from a strongly defocused lowcontrast image of a rough surface is scanned, and the contrast value, $C=\sigma_{\mathrm{l}} /\langle I\rangle$, is processed. A relatively low degree of spatial and temporal coherence, combined with a relatively high-image aperture and a detector aperture (which is much wider than the nominal speckle width of the corresponding highly coherent speckle pattern) led to important instrumental advantages, e.g., illumination by an incandescent lamp, simple photodetectors, short measuring times and simple, inexpensive, compact construction. The superposition of uniform intensity to the phase contrast structure, which leads to a strictly monotonic dependence of the measured contrast over a very wide range of the roughness values $R_{\mathrm{a}}$ is of great importance. Practical measurements of metallic surface standards are reported and discussed, and the theoretical aspects of the superposition of uniform intensity are pointed out with the help of a new analytic expression for the stochastic contrast.
\end{abstract}

\section{Introduction}

Surface roughness measurements are important in industrial production. So far, the mechanical profilometer is used mainly for roughness measurements. What is required, however, is a contactless measuring method well suited for automated production control. The method proposed in this paper is a modified speckle contrast technique [1-3]. In figure 1 , a rough surface is illuminated and imaged via a beamsplitter, BS, and a lens, L, into the image plane, IP. A defocused speckle structure is scanned by a pinhole in front of a photodetector. The contrast $C$ is defined by the ratio of the standard deviation of the intensity $\sigma_{1}$ to the mean intensity $\langle I\rangle$

$$
C=\frac{\sigma_{\mathrm{I}}}{\langle I\rangle}
$$

For practical measurements, $C$ is calculated with an in-line microcomputer from a sufficiently high number of discrete intensity values.

For monochromatic light (and a great number of statistically independent surface elements), the dependence of the contrast $C$ on the standard deviation, $\sigma_{\mathrm{h}}$, of the profile heights, $h(x)$, is given by an ascending curve beginning with $C=0$ for an ideal mirror $\left(\sigma_{\mathrm{h}}=0\right)$ and reaching saturation $C \approx 1$ at $\sigma_{\mathrm{h}} \approx \lambda / 4$. Machined metallic surfaces, however, show a $\sigma_{\mathrm{h}}$ between 0.05 and $10 \mu \mathrm{m}$. In addition, contrast depends on second-and higher-order statistical parameters of the surface, usually not known. Therefore, the ascending curve is not adequate for metal surfaces. 


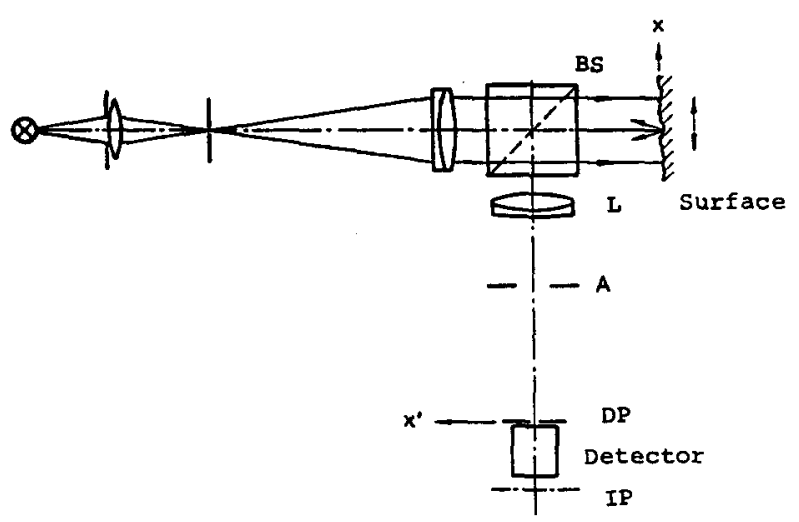

Figure 1. Arrangement for polychromatic speckle contrast measurements. $B S=$ beamsplitter; $L=$ imaging lens, with aperture $A ; I P=$ image plane; and $D P=$ defocused plane.

Using polychromatic light and considering the finite coherence length, the contrast can be expected to decrease with increasing $\sigma_{\mathrm{h}}$, because the interference of contributions of peaks and valleys leads to low contrast. Measurements with light from a tungsten zirconium arc have been reported by Sprague [1], but the shape of the curve and the measuring range could not be confirmed. Comparison of the results of Nakagawa and Asakura [4, 5], using a broad range of parameters, and the results presented here, repeating the measurements of Sprague [1] by carefully avoiding stray light, does not show monotonic falling curves over an appropriate range of roughness values. Even ascending curves were obtained using a combination of semiconductor lasers of different mean wavelength [6].

\section{Stochastic phase contrast with incoherent superposition of uniform intensity}

Using broad spectral response of an unfiltered tungsten incandescent lamp with a broadband photomultiplier, together with reduced spatial coherence and a highaperture imaging lens, we obtained a low contrast intensity structure in the defocused detector plane, DP (figure 3). This structure (figure 2), looks more like phase contrast by defocusing rather than a speckle pattern $[7,8]$. It was scanned with a detector pinhole roughly ten times larger than the corresponding speckle size of high-coherence illumination and will be called in this paper, stochastic phase contrast by defocusing. For a monotonically falling curve with a sufficiently steep slope for a reliable characteristic, the superposition of an incoherent background was essential [10]. This superposition via the beamsplitter, BS, the beam attenuator, BA, and a plane mirror, $M$ (figure 3) reduces the contrast for rough samples more severely than for samples of smaller roughness. In figure $4, t$ is the ratio of the uniform intensity, $I_{\mathrm{u}}$, to the sample intensity, $I_{\mathrm{s}}$, for vanishing roughness

$$
t=\frac{I_{\mathrm{u}}}{\left.I_{\mathrm{s}}\right|_{\mathrm{o}_{\mathrm{h}=0}}}
$$

measured in the detector plane. For $t=0$, no intensity is superposed.

In figure 5 a nearly linear curve is obtained in a $\log -\log$ representation. The samples used for figures 4 and 5 were metallic surface standards. The uncertainties 


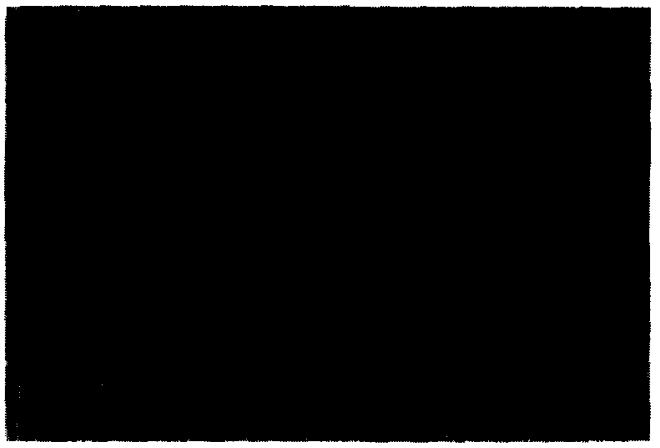

(a)

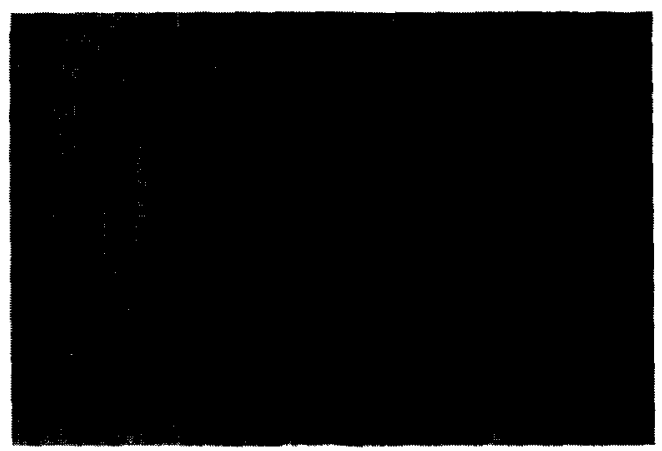

(b)

Figure 2. Stochastic phase contrast structure of two roughness standards: (a) fine-ground surface with arithmetic average roughness value $R_{\mathrm{a}}=0.06 \mu \mathrm{m}$; and $(b)$ ground surface with $R_{\mathrm{a}}=2.75 \mu \mathrm{m}$.

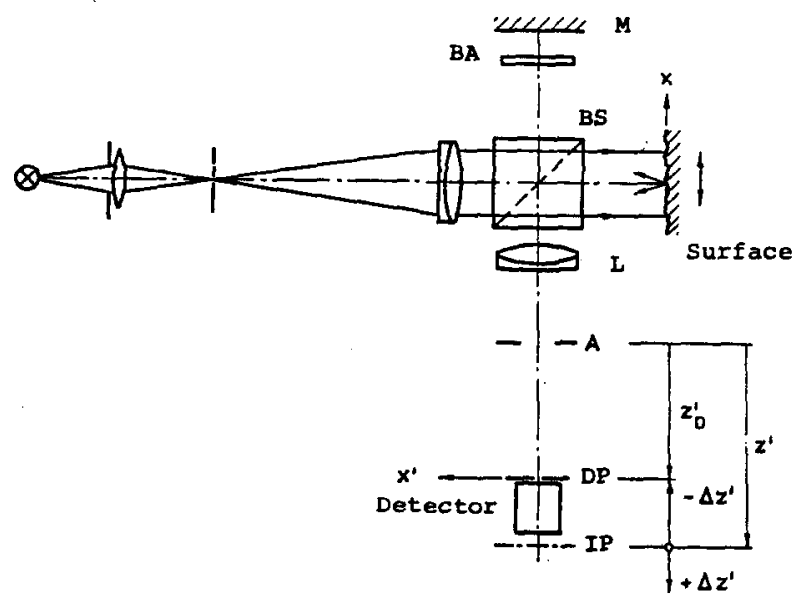

Figure 3. Arrangement for the measurement of the stochastic phase contrast structure with superposed incoherent intensity via beamsplitter, BS; beam attennator, BA; and mirror, $\mathrm{M}$. $\mathrm{L}=$ imaging lens; $\mathrm{A}=$ imaging aperture; $\mathrm{IP}=$ image plane; and $\mathrm{DP}$ $=$ defocused plane. 


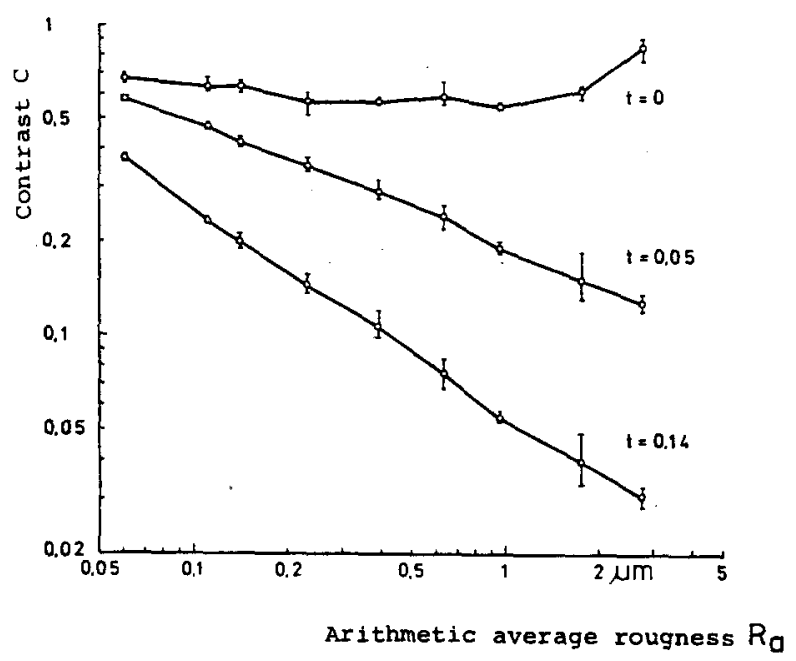

Figure 4. Contrast measured for three different values of $t$ for incoherent superposed intensity. For $t=0$, superposition of the faces of a beamsplitter cube with single layer antireflection coatings, $t=0 \cdot 05$; beamsplitter without coating, $t=0 \cdot 14$.

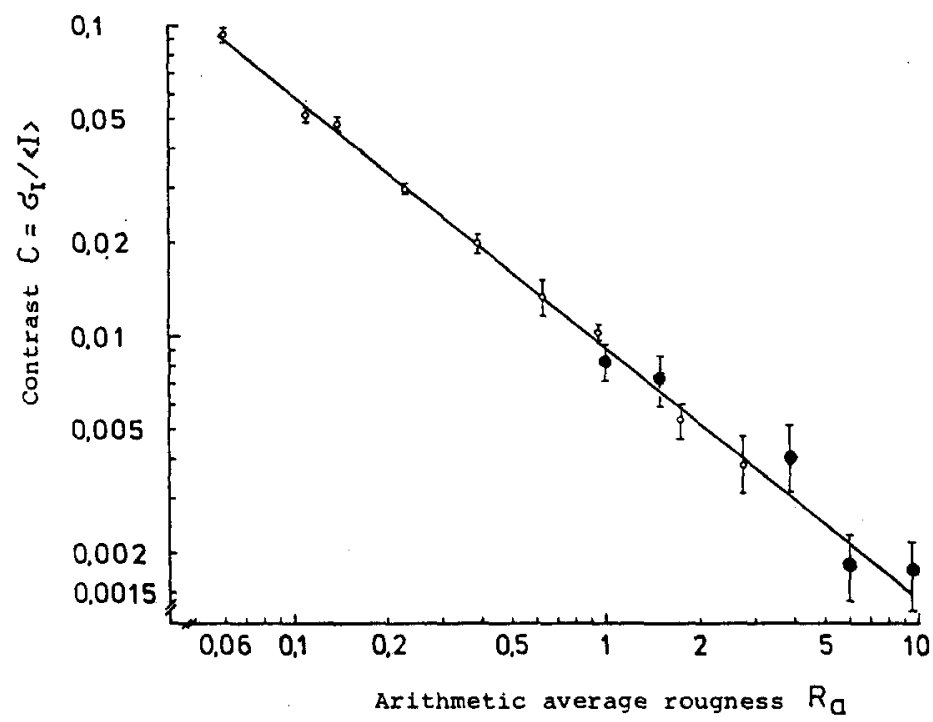

Figure 5. Measured contrast $C$ over arithmetic average roughness value $R_{\mathrm{a}}$. The scanning lengths on metallic roughness standards were $7 \mathrm{~mm}$ for six different surface positions. $\mathrm{O}=$ ground surfaces; $\mathbf{O}=$ planned surfaces.

marked by the vertical bars are due mainly to local roughness variations on the standards. These uncertainties can be reduced by scanning several parallel traces simultaneously with a detector array and averaging the contrasts.

\section{Theoretical considerations}

By considering the propagation of mutual coherence [9] from the source to the rough surface and the detector, we arrived at a very general expression for the variance and mean intensity. An analytical expression was found for the contrast by 
assuming gaussian distribution of profile heights and a four-dimensional model of $n^{4}$ equally shaped facets of normalized profile autocorrelation interlaced with a twodimensional model of facets of spatial coherence necessary to integrate a fourthorder characteristic function. The theory is valid for high-coherence speckle as well as for stochastic phase contrast with or without superimposed intensity. The derivation will be given in detail in another paper. Given a mean wavelength, $\lambda_{0}$, mean wavenumber, $k_{0}=2 \pi / \lambda_{0}$, with $W$ being the wavenumber of the spectral width, we have, for a gaussian spectral response

$$
S(k)=\text { const } \exp \left\{-\frac{\left(k-k_{0}\right)^{2}}{2 W^{2}}\right\} .
$$

For the normalized profile autocorrelation function with $x_{\mathrm{a}}$ as the equivalent width, we write

$$
\frac{R_{\mathrm{h}}\left(x_{i}, x_{k}\right)}{\sigma_{\mathrm{h}}^{2}}= \begin{cases}1, & \text { for }\left|x_{i}-x_{k}\right| \leqslant x_{\mathrm{a}} \\ 0, & \text { otherwise. }\end{cases}
$$

We introduce the interlacing parameters $v_{1}$ and $v_{2}$

$$
\begin{aligned}
& v_{1}=(2 n-d)(d-1) \\
& v_{2}=n(2 d-2)(2 d-3)-\frac{10}{3} d^{3}+8 d^{2}-\frac{14}{3} d
\end{aligned}
$$

with $n=x_{\mathrm{B}} / x_{\mathrm{a}}$, where $x_{\mathrm{B}}$ is the width of the contributing interval on the surface

$$
x_{\mathrm{B}}=\left(\beta_{\mathrm{D}}^{\prime}-\beta^{\prime}\right) \mathrm{D} / \beta_{\mathrm{D}}^{\prime} \beta^{\prime},
$$

where $D$ is the diameter of the imaging aperture $\mathrm{A}$ in figure $3, \beta^{\prime}$ is the transverse magnification $\beta^{\prime}=-z^{\prime} / f^{\prime}$, and $\beta_{\mathrm{D}}^{\prime}$ is defined in analogy as $\beta_{\mathrm{D}}^{\prime}=-z_{\mathrm{D}}^{\prime} / f^{\prime}$ (see figure 3 ). With $x_{\mathrm{c}}$ as the width of the spatial coherence, $d$ is defined as $d=x_{\mathrm{c}} / x_{\mathrm{a}}$. The stochastic contrast $C$ according to (1) is

$$
\begin{aligned}
C= & {\left[\frac{v_{1}}{\sqrt{\left(1+16 W^{2} \sigma_{\mathrm{h}}^{2}\right)}}\left(1+\exp \left\{\frac{-16 k_{0}^{2} \sigma_{\mathrm{h}}^{2}}{1+16 W^{2} \sigma_{\mathrm{h}}^{2}}\right\}\right)\right.} \\
& +\frac{2 v_{2}}{\sqrt{ }\left[\left(1+12 W^{2} \sigma_{\mathrm{h}}^{2}\right)\left(1+4 W^{2} \sigma_{\mathrm{h}}^{2}\right)\right]}\left(\exp \left\{\frac{-4 k_{0}^{2} \sigma_{\mathrm{h}}^{2}}{1+4 W^{2} \sigma_{\mathrm{h}}^{2}}\right\}+\exp \left\{\frac{-12 k_{0}^{2} \sigma_{\mathrm{h}}^{2}}{1+12 W^{2} \sigma_{\mathrm{h}}^{2}}\right\}\right) \\
& \left.-\frac{2\left(v_{1}+2 v_{2}\right)}{1+8 W^{2} \sigma_{\mathrm{h}}^{2}} \exp \left\{\frac{-8 k_{0}^{2} \sigma_{\mathrm{h}}^{2}}{1+8 W^{2} \sigma_{\mathrm{h}}^{2}}\right\}\right]^{1 / 2} \\
& \times\left[\left(v_{1}+n\right) t+n+\frac{v_{1}}{\sqrt{ }\left(1+8 W^{2} \sigma_{\mathrm{h}}^{2}\right)} \exp \left\{\frac{-k_{0}^{2} 4 \sigma_{\mathrm{h}}^{2}}{1+8 W^{2} \sigma_{\mathrm{h}}^{2}}\right\}\right]^{-1},
\end{aligned}
$$

where $t$ is the superposition factor defined by (2). In figure 6 the contrast is plotted over the standard deviation of the profile heights, $\sigma_{h}$, with three values of correlation width, $x_{\mathrm{a}}=50,25$ and $12.5 \mu \mathrm{m}$ and two values of superposition, namely, $t=0$ (straylight carefully avoided) and $t=1.4$ (full superposition without BA in figure 3 ). The solid lines in figure 6 shows the result for partial spatial coherence, $x_{\mathrm{c}}=108 \mu \mathrm{m}$ and the dashed lines show the limiting case, $x_{c} \rightarrow \infty$. The influence of spatial coherence is clearly seen by the separation of the corresponding curves. 
The influence of $t$ (incoherent background) is shown in more detail in figure 12 of Leonhardt and Pfister [10] where another analytic expression for $C$ with $x_{c} \rightarrow \infty$ is evaluated. It can be noted (see also figure 4) that even a very low incoherent background severely reduces the contrast. However, the reduction due to $t$ is not uniform over the roughness, but shows a marked decline immediately after the contrast maximum. This decline is more distinct for a small correlation width $x_{\mathrm{a}}$, which is smoothed out with both decreasing temporal coherence (see figure 12 of Leonhardt and Pfister [10]) and spatial coherence (see figure 6) resulting in a steeper overall shape of the contrast curve and a shift of the maximum to smaller roughness values, extending the useful measuring range by a factor of $\sim 2$ for $t=1 \cdot 4$. The marked points in figure 6 are measured contrast values transferred from figure 5 . For monochromatic light, calculations with the appropriate parameters in (8) show good agreement with the measurements of Ohtsubo and Asakura [11].

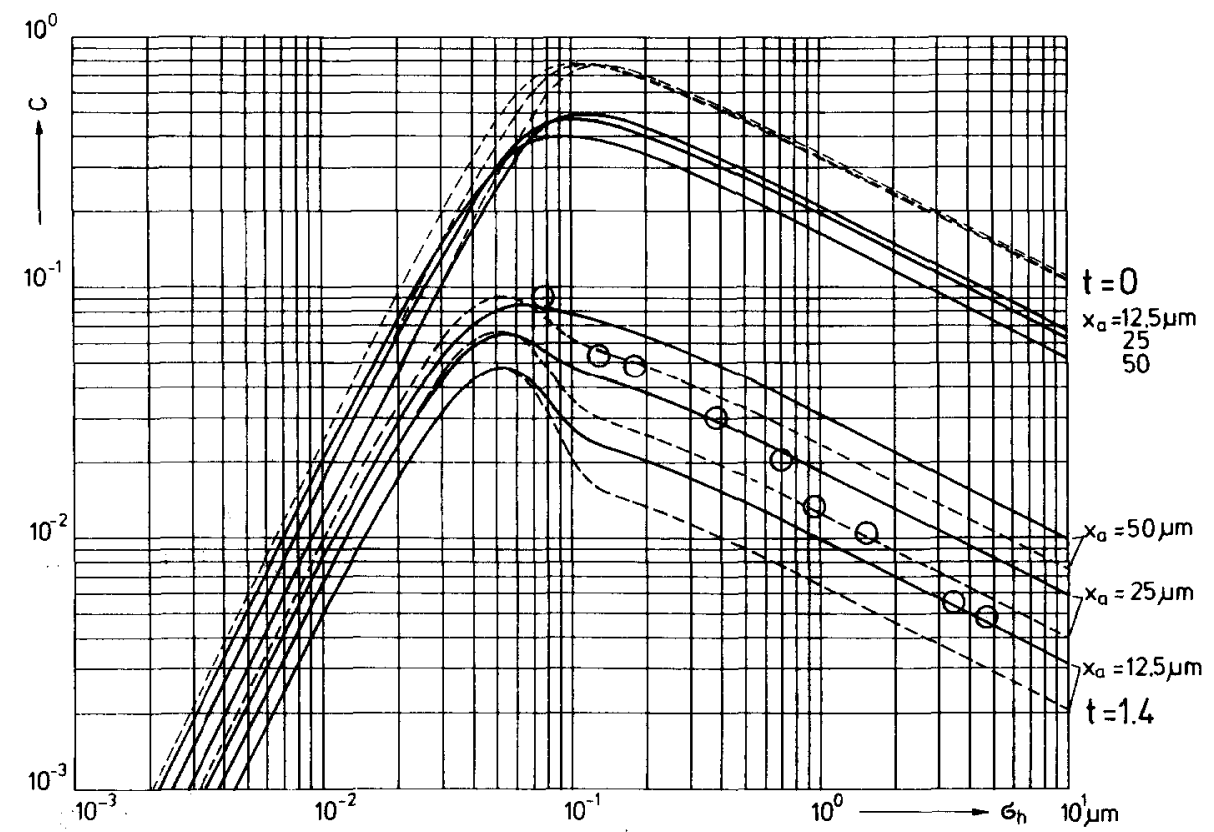

Figure 6. Stochastic contrast from equation (8) over the standard deviation $\sigma_{\mathrm{h}}$ of the profile heights for three different values of surface autocorrelation width with $x_{\mathrm{a}}=50,25$ and $12.5 \mu \mathrm{m}$ and two values of incoherent superposition, $t=0$ and 1.4. Mean wavenumber, $k_{0}=11.5 \mu \mathrm{m}^{-1}$; spectral bandwidth, $W=2.0 \mu \mathrm{m}^{-1}$; aperture diameter, $D=13 \mathrm{~mm}$; $\beta^{\prime}=8$ and $\beta_{\mathrm{D}}^{\prime}=11 \cdot 25$. Solid lines indicate spatial coherence of the light, $x_{\mathrm{c}}=108 \mu \mathrm{m}$; and dashed lines show the limiting case, $x_{\mathrm{c}} \rightarrow \infty$.

\section{Conclusions}

The work presented here is a step forward towards a contactless roughness measuring device. From figures 5 and 6 a very large measuring range of $R_{\mathrm{a} \text { max }} / R_{\mathrm{a} \min } \approx 200$ is obtained, which fits precisely the demands of machine-finished metal surfaces. All the alterations from the speckle contrast described in this paper lead to important instrumental advantages for a stable, reliable and compact roughness sensor. The theory developed shows clearly the dependence of the contrast on the most important parameters. 


\section{Acknowledgment}

The authors thank E. Kaufmann for mathematical help with the integration by the interlaced double-facet model.

Une nouvelle méthode pour mesurer la rugosité de surface dans le domaine de $R_{\mathrm{a}}=0,05 \mu \mathrm{m}$ à $10 \mu \mathrm{m}$ est présentée. L'information d'une image fortement défocalisée à bas contraste de la surface rugueuse est obtenue par balayage et la valeur du contraste $C=\sigma_{\mathrm{I}} /\langle I\rangle$ est traitée. Un degré de cohérence spatiale et temporelle relativement bas combiné à une ouverture image relativement élevée et une ouverture de détecteur qui est beaucoup plus grande que les dimensions nominales du speckle de la figure de speckle qui lui correspond en éclairage très cohérent, conduisent à d'importants avantages instrumentaux (éclairage par une lampe à incandescence, photodétecteurs simples, temps de mesure courts, et construction simple, compacte et bon marché). La superposition d'un éclairement uniforme à la structure de contraste de phase est d'une importance essentielle pour conduire à une variation très régulière du contaste mesuré dane thr dornaine très étendh de valeurs $\boldsymbol{R}_{\mathrm{a}}$ de la rugosité.

Des résultats pratiques de mesures sur des étalons à surface métallique sont présentés et discutés et les aspects théoriques de la superposition de l'éclairement uniforme sont développés à l'aide d'une expression analytique du contraste stochastique.

Eine neue Methode zur Messung der Oberflächenrauhigkeit im Bereich $\mathbf{R}_{\mathrm{a}} \approx 0,05 \mu \mathrm{m}$ bis $10 \mu \mathrm{m}$ wird präsentiert. Ein stark defokussiertes kontrastarmes Bild der Oberfläche wird abgetastet und der Kontrastwert $\mathrm{C}=\sigma_{\mathrm{I}} /\langle I\rangle$ wird verarbeitet. Ein relative geringer Grad räumlicher und zeitlicher Kohärenz, verbunden mit einer relativ großen Abbildungsapertur und einer über die nominale Specklegröße des entsprechenden hochkohärenten Specklemusters hinausgehenden Detektorapertur, führten zu wichtigen instrumentellen Vorteilen (Beleuchtung durch eine Glühlampe, einfache Photodetektoren, kurze Meßzeiten, sowie einfache, billige und kompakte Konstruktion). Von besonderer Wichtigkeit ist die Überlagerung der Phasenkontraststruktur mit einer gleichförmigen Intensität, die zu einer strikt monotonen Abhängigkeit des gemessenen Kontrasts über einen sehr weiten Bereich der Rauhigkeitswerte $\mathbf{R}_{\mathrm{a}}$ führt.

Es wird von praktischen Messungen an metallischen Oberflächen berichtet und theoretische Aspekte der Überlagerung der gleichförmigen Intensität werden mit Hilfe einer neuen analytischen Formel für den stochastischen Kontrast erörtert.

\section{References}

[1] Sprague, R. A., 1972, Appl. Optics, 11, 2811.

[2] Goodmann, J. W., 1975, Laser Speckle and Related Phenomena, edited by J. C. Dainty (Berlin: Springer-Verlag).

[3] Parry, G., 1975, Laser Speckle and Related Phenomena edited by J. C. Dainty (BerlinSpringer-Verlag).

[4] Nakagawa, K., and Asakura, T., 1979, Optica Acta, 26, 951.

[5] Nakagawa, K., and Asakura, T., 1979, Appl. Optics, 18, 3725.

[6] Rac, N., 1979, Thesis, University Stuttgart.

[7] Michel, K., 1950, Die Grundlagen der Theorie des Mikroskopes (Stuttgart: Wissenschaftliche Verlagsgesellschaft).

[8] Walther, A., 1965, Applied Optics and Optical Engineering, Vol. 1, edited by R. Kingslake (New York: Academic Press), p. 283.

[9] Beran, M. J., and Parrent, G. B., 1964, Theory of Partial Coherence (Englewood Cliffs, N.J.: Prentice-Hall).

[10] Leonhardt, K., and Pfister, B., 1981, Optik, 58, 297.

[11] Ohtsubo, J., and Asakura, T., 1976, Optik, 45, 65. 